\title{
Antioxidant and Anti-infective Potential of Ethanolic Extract of Eriobotrya bengalensis (Roxb.) Hook. f.: Phytochemicals Investigation and Molecular Docking Studies
}

\author{
Nagaraju Jalli ${ }^{1}$, Santhi Sri K.V. ${ }^{1 *}$, Sairengpuii Hnamte ${ }^{2}$, Subhaswaraj Pattnaik ${ }^{2}$, \\ Parasuraman Paramanantham ${ }^{2}$ and Busi Siddhardha2* \\ ${ }^{1}$ Department of Foods and Nutritional Sciences, Acharya Nagarjuna University, Guntur - 522 510, India. ${ }^{2}$ Department \\ of Microbiology, School of Life Sciences, Pondicherry University, Puducherry - 605 014, India.
}

\begin{abstract}
In India, north-east region holds a special position of having diverse range of plants belonging to endemic species with widespread ethnomedicinal properties which remain unexplored till date. In the present study, Eriobotrya bengalensis (Roxb.) Hook. f. extract was evaluated for its radical scavenging activity and ability to combat quorum sensing regulated bacterial virulence in Pseudomonas aeruginosa PAO1. The ethanolic leaf extract of $E$. bengalensis (Roxb.) Hook. f. exhibited a concentration dependent radical scavenging of highly reactive DPPH and hydroxyl radicals with a scavenging percentage of 76.84 \pm 4.72 and $67.37 \pm 4.35 \%$ respectively at a concentration of $500 \mu \mathrm{g} / \mathrm{ml}$. E. bengalensis (Roxb.) Hook. f. also showed significant reducing power and relatively high ascorbic acid equivalent. The plant extract was also evaluated for its ability to down-regulate the production of quorum sensing (QS) regulated pathogenic determinants in P. aeruginosa PAO1. The violacein production in Chromobacterium violaceum and pyocyanin production in $P$. aeruginosa PAO1 was greatly inhibited on treatment with sub-MIC of $E$. bengalensis (Roxb.) Hook. $f$. with an inhibition of $79.58 \pm 4.13$ and $76.31 \pm 4.03 \%$ respectively. The anti-biofilm activity was further confirmed by confocal laser scanning microscopic (CLSM) analysis. The anti QS activity of $E$. bengalensis (Roxb.) Hook. f. was further corroborated by molecular docking studies which provides an insight into the mechanism of QS inhibition. The present result will provide novel leads to the application of unexplored plant species towards the development of novel anti-infectives in the post-antibiotic era.
\end{abstract}

Keywords: Eriobotrya bengalensis, Antioxidant, Biofilm, Quorum sensing, Molecular docking.

*Correspondence: siddhardha.busi@gmail.com; +91 9597761788

(Received: 12 December 2018; accepted: 02 February 2019)

Citation: Nagaraju Jalli, Santhi Sri K.V., Sairengpuii Hnamte, Subhaswaraj Pattnaik, Parasuraman Paramanantham and Busi Siddhardha, Antioxidant and Anti-infective Potential of Ethanolic Extract of Eriobotrya bengalensis (Roxb.) Hook. f.: Phytochemicals Investigation and Molecular Docking Studies, J Pure Appl Microbiol., 2019; 13(1):361-370 doi: 10.22207/JPAM.13.1.40

(C) The Author(s) 2019. Open Access. This article is distributed under the terms of the Creative Commons Attribution 4.0 International License which permits unrestricted use, sharing, distribution, and reproduction in any medium, provided you give appropriate credit to the original author(s) and the source, provide a link to the Creative Commons license, and indicate if changes were made. 


\section{INTRODUCTION}

In the living system, during the metabolic processes free radicals are generated as intermediate byproducts. Besides, the generation of free radicals is also associated with the inadvertent exposure to radiation, environmental pollutants and stress conditions ${ }^{1}$. The production of the free radicals and their subsequent disposal out of the body is carried out by the endogenous antioxidant machinery. However, when the level of these free radicals surpasses beyond a certain limitation, the endogenous system fails to discharge these free radicals leading to severe oxidative stress. The emergence of oxidative stress is normally associated with the damage to the biological macromolecules including carbohydrates, proteins, lipids and nucleic acids leading to several disease conditions and metabolic disorders ${ }^{2}$. In this condition, it is important to supply antioxidants exogenously to maintain the endogenous antioxidant machinery and subsequent radical scavenging. The exogenous antioxidants are basically derived from different food and plant-based phytochemicals with special reference to polyphenol group of compounds which are reported to exhibit significant antioxidant activity ${ }^{3}$. The secondary metabolites synthesized by plants constitutively scavenge the free radicals and thereby maintain the harmonic balance in the endogenous antioxidant machinery ${ }^{4}$.

The persistent bacterial infections associated with high morbidity and mortality is generally established through the production of highly reactive oxygen species (ROS) and related oxidative stress ${ }^{5}$. P. aeruginosa is an important nosocomial pathogen, generally associated with pulmonary infections and other hospital-acquired infections in the immunocompromised individuals. The majority of chronic infections by $P$. aeruginosa could be attributed to the highly synchronized QS regulatory network. The QS network controls the production of an array of virulence phenotypes, especially pyocyanin which is associated with cytotoxicity during host infection by inducing oxidative stress ${ }^{6}$. In recent times, the preventive and curative properties of plant-derived natural products were exploited to down regulate the QS regulated behaviours especially biofilm formation and development in $P$. aeruginosa $\mathrm{PAO}^{7}$. E. bengalensis (Roxb.) Hook. f. belongs to family Rosaceae and commonly known as 'Bengal' loquat. The genus Eriobotrya has been used as food ingredient in majority of Asian countries. Besides, the leaf and fruit of the plant are used for the treatment of cough, asthma and other pulmonary infections due to the presence of phenolic compounds and triterpenes ${ }^{8}$. Owing to the pharmacological potential carried by different Eriobotrya sp., in the present study the antioxidant, anti QS and anti-biofilm activity of $E$. bengalensis (Roxb.) Hook. f. extract was evaluated. The anti QS and anti-biofilm potential of E. bengalensis (Roxb.) Hook. f. was further confirmed by in silico studies.

\section{MATERIALS AND METHODS}

\section{Collection of plant material and preparation of crude extract}

The leaf samples of $E$. bengalensis(Roxb.)

Hook. f. plant were collected from Mizoram, India. The leaf samples were washed, dried and homogenized to fine powder. Five grams of powdered sample was soaked in the extraction medium, ethanol $(50 \mathrm{ml})$ for $48-72 \mathrm{~h}$. After the incubation, the plant infusions were filtered and the residues were concentrated by rotary evaporator at $40^{\circ} \mathrm{C}$.

\section{Chemicals and reagents}

The chemicals used are 2, 2-Diphenyl1-picrylhydrazyl (DPPH), 2-deoxy ribose, thiobarbituric acid (TBA) and acridine orange. The reagents used in the study are trichloroacetic acid (TCA), hydrochloric acid $(\mathrm{HCl})$, sulphuric acid $\left(\mathrm{H}_{2} \mathrm{SO}_{4}\right)$, ferric chloride $\left(\mathrm{FeCl}_{3}\right)$, ammonium molybdate, potassium ferricyanide $\left[\mathrm{K}_{3} \mathrm{Fe}(\mathrm{CN})_{6}\right]$, ethylene diamine tetraacetic acid (EDTA) and sodium hydroxide $(\mathrm{NaOH})$. All the chemicals and reagents were procured from HiMedia laboratories, Mumbai, India.

\section{Determination of antioxidant activity DPPH free radical scavenging assay}

The free radical scavenging effect of $E$. bengalensis (Roxb.) Hook. f. extract was evaluated using DPPH radicals as described by Pavithra and Vadivukarasi (2015) ${ }^{9}$. Briefly, $0.2 \mathrm{mM}$ DPPH was prepared in methanol and to the DPPH solution, different concentration of the plant extract $(100-500 \mu \mathrm{g} / \mathrm{ml})$ were added and incubated in the dark at $27 \pm 2^{\circ} \mathrm{C}$ for $30 \mathrm{~min}$. After the incubation, the absorbance of the reaction mixture was determined at $517 \mathrm{~nm}$. A control experiment was 
also set up without the plant extract. The DPPH radical scavenging activity (\%) was calculated as per the following equation. The $\mathrm{IC}_{50}$ (concentration at which $50 \%$ DPPH radicals get scavenged) value was also determined.

\begin{tabular}{|c|c|}
\hline & $\begin{array}{l}\text { (Optical density of the } \\
\text { control - Optical density } \\
\text { of the sample) }\end{array}$ \\
\hline $\begin{array}{l}\text { inhibition } \\
\text { (\%) }\end{array}$ & $\begin{array}{l}\text { Optical density } \\
\text { of the control }\end{array}$ \\
\hline
\end{tabular}

\section{Determination of reducing power}

The ability of $E$. bengalensis (Roxb.) Hook. f. extract in reducing the ferric $\left(\mathrm{Fe}^{3+}\right)$ to ferrous $\left(\mathrm{Fe}^{2+}\right)$ form by forming Prussian blue complex at $700 \mathrm{~nm}$ was evaluated as described by Singh et al. (2015) with slight modification ${ }^{10}$. Briefly, different concentrations of plant extract $(100-500 \mu \mathrm{g} / \mathrm{ml})$ were mixed with phosphate buffer $(0.2 \mathrm{M}, \mathrm{pH}$ 6.6) and $1 \%\left[\mathrm{~K}_{3} \mathrm{Fe}(\mathrm{CN})_{6}\right]$. The reaction mixture was heated at $50{ }^{\circ} \mathrm{C}$ for $20 \mathrm{~min}$ followed by addition of TCA $(10 \% \mathrm{w} / \mathrm{v})$ and the solution was pelleted at $10,000 \mathrm{rpm}$ for $10 \mathrm{~min}$. The supernatant was diluted with deionized water and freshly prepared $\mathrm{FeCl}_{3}(0.1 \% \mathrm{w} / \mathrm{v})$ solution. The absorbance of the reaction mixture was measured at $700 \mathrm{~nm}$.

\section{Hydroxyl radical scavenging activity}

The hydroxyl radical scavenging potential of E. bengalensis (Roxb.) Hook. f. extract was determined as described by Tounkara et al. (2014) with slight modifications ${ }^{11}$. Briefly, a reaction mixture was prepared by addition of sodium phosphate buffer(0.2 M, pH 7.0), 2-deoxyribose $(10 \mathrm{mM}), \mathrm{FeSO}_{4}$-EDTA $(10 \mathrm{mM}), \mathrm{H}_{2} \mathrm{O}_{2}(10 \mathrm{mM})$ and different concentration of plant extract (100-500 $\mu \mathrm{g} / \mathrm{ml})$. The reaction mixture was incubated at $37{ }^{\circ} \mathrm{C}$ for $4 \mathrm{~h}$ followed by addition of TCA $(2.8 \%$ $\mathrm{w} / \mathrm{v})$ and TBA ( $1 \% \mathrm{w} / \mathrm{v}$ in $\mathrm{NaOH}$ ) and boiled for 10 min followed by cooling to room temperature. A control experiment was also prepared without the addition of plant extract. The absorbance was determined at $532 \mathrm{~nm}$. The hydroxyl radical scavenging efficacy was determined using the following equation,

\begin{tabular}{|c|c|}
\hline & $\begin{array}{l}\text { (Absorbance of } \\
\text { the control - Absorbance of } \\
\text { the treated sample) }\end{array}$ \\
\hline (\%) & $\begin{array}{c}\text { Absorbance of } \\
\text { the control }\end{array}$ \\
\hline
\end{tabular}

\section{Total antioxidant activity}

Briefly, different concentrations of leaf extract $(100-500 \mu \mathrm{g} / \mathrm{ml})$ were mixed with reagent solution $\left(0.6 \mathrm{M} \mathrm{H}_{2} \mathrm{SO}_{4}, 28 \mathrm{mM}\right.$ sodium phosphate and $4 \mathrm{mM}$ ammonium molybdate). The reaction mixture was incubated at $95^{\circ} \mathrm{C}$ for $90 \mathrm{~min}$ followed by cooling to room temperature and the absorbance was determined at $695 \mathrm{~nm}$. The total antioxidant activity was expressed as ascorbic acid equivalents (AAE) ${ }^{12}$.

Determination of anti QS and anti-biofilm activity Bacterial strains and maintenance of culture

For determining the anti QS activity of E. bengalensis (Roxb.) Hook. f., C. violaceum (MTCC 2656)was used as biomarker strain and $P$. aeruginosa PAO1 was used as test microorganism. The anti-biofilm activity was evaluated against the persistent biofilm architecture in $P$. aeruginosa PAO1.

As per the recommendation of Clinical and Laboratory Standards Institute (CLSI, 2014), the MIC of E. bengalensis (Roxb.) Hook. f. extract was determined using broth macrodilutions method. All the anti QS and anti-biofilm activities were performed at sub-MIC concentration ${ }^{13}$.

Anti QS activity against biomarker strain, Chromobacterium violaceum

\section{Violacein inhibition activity}

The effect on violacein production by C. violaceum on treatment with $E$. bengalensis (Roxb.) Hook. f. was evaluated according to ${ }^{14}$. Briefly, C. violaceum was grown in presence of subMIC of $E$. bengalensis (Roxb.) Hook. f. at $30^{\circ} \mathrm{C}$ for $24 \mathrm{~h}$. The overnight culture was pelleted $(10,000$ $\mathrm{rpm}, 10 \mathrm{~min}$ ) to precipitate the insoluble violacein and DMSO was added to the pellet to solubilize the violacein. The reaction mixture was recentrifuged (10,000 rpm, $10 \mathrm{~min}$ ) and the absorbance was measured at $585 \mathrm{~nm}$. A control experiment was also performed without the plant extract. The inhibition in violacein production was quantified by the following formula,

$\%$ inhibition $=\left[\left(O D_{\text {control }}-O D_{\text {treated }}\right) / O D_{\text {control }}\right] \times 100$.

Anti QS and anti-biofilm activity against $P$. aeruginosa PAO1

Pyocynanin inhibition activity

The pyocyanin pigment from overnight grown $P$. aeruginosa $\mathrm{PAO} 1$ was extracted by adding 
chloroform into the cell-free culture supernatant (3:5). The reaction mixture was vortexed and the pyocyanin containing organic phase was re-extracted with $\mathrm{HCl}(0.2 \mathrm{M})$. The reaction mixture was vortexed and the optical density was measured at $520 \mathrm{~nm}$. A control experiment was also performed without the plant extract ${ }^{15}$. The inhibition in pyocyanin production was quantified by the following formula,

$\%$ inhibition $=\left[\left(O D_{\text {control }}-O D_{\text {treated }}\right) / O D_{\text {control }}\right] \times 100$.

\section{Effect on bacterial motility}

The effect of $E$. bengalensis (Roxb.) Hook. f. on swimming and swarming motility was determined according to Packiavathy et al. $(2014)^{16}$. Briefly, the plant extract treated $P$. aeruginosa $\mathrm{PAO} 1$ was point inoculated into specific swimming medium (composed of $1 \%$ tryptone, $0.5 \% \mathrm{NaCl}$ and $0.3 \%$ agar agar) and swarming medium (composed of $1 \%$ bacteriological peptone, $05 \% \mathrm{NaCl}, 0.5 \%$ glucose and $0.5 \%$ agar agar) and incubated at $37^{\circ} \mathrm{C}$ for $24 \mathrm{~h}$.

\section{Anti-biofilm activity using microscopic observation}

The anti-biofilm activity of $E$. bengalensis (Roxb.) Hook. f. was determined as described by Zhou et al. (2018) with slight modifications ${ }^{17}$. Briefly, E. bengalensis (Roxb.) Hook. f. extract treated $P$. aeruginosa $\mathrm{PAO} 1$ were allowed to grow in the glass coverslips at $37^{\circ} \mathrm{C}$ for $24 \mathrm{~h}$. The attached biofilms on the coverslip were stained

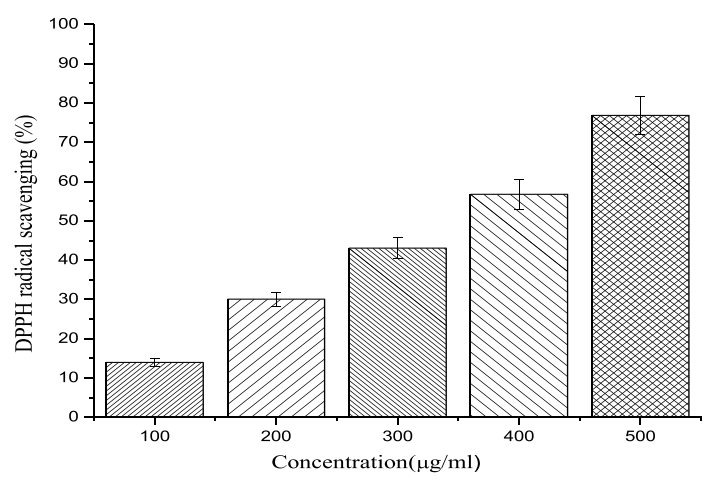

Fig. 1. DPPH free radical scavenging activity of different concentrations $(100-500 \mu \mathrm{g} / \mathrm{ml})$ of ethanolic leaf extract of $E$. bengalensis (Roxb.) Hook. with acridine orange $(0.1 \% \mathrm{w} / \mathrm{v})$ for 15 min under dark condition. The excess stains were then removed with PBS and observed under CLSM (LSM 710, Carl Zeiss, Germany). A control experiment was also performed for $P$. aeruginosa PAO1 without the plant extract.

Gas Chromatography-Mass Spectrometric (GCMS) analysis

The phytochemical profile of $E$. bengalensis (Roxb.) Hook. f. was analyzed by GC-MS. Helium was used as a carrier gas with a constant flow rate of $1.0 \mathrm{ml} / \mathrm{min}$. The injector was operated at $250^{\circ} \mathrm{C}$ and the oven temperature was programmed as follows: $60^{\circ} \mathrm{C}$ for $15 \mathrm{~min}$, then gradually increased to $280^{\circ} \mathrm{C}$ at $3 \mathrm{~min}$. The phytochemicals present in the extract were identified based on the obtained spectrum, retention time and NIST library ${ }^{18}$.

\section{Molecular docking studies}

The docking studies were carried out in Schrodinger maestro software version 9.2 and the binding affinity of the identified phytochemicals from GC-MS analysis and natural autoinducer to transcriptional receptor, LasR were analyzed. The ligand binding domain of LasR protein's 3D-structure file (PDB ID: 2UV0) was obtained from Protein Data Bank. The LasR protein was then subjected to preparation in protein preparation wizard of Schrodinger maestro software version 9.2. Grid generation was performed in Glide, version 5.7 in Schrodinger maestro software, for Las $R$ protein grid were defined around the active

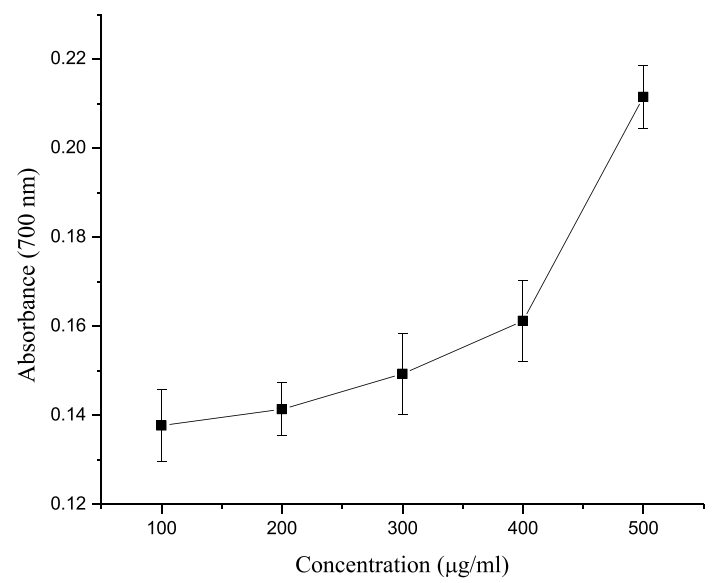

Fig. 2. Determination of reducing power of different concentrations $(100-500 \mu \mathrm{g} / \mathrm{ml})$ of ethanolic leaf extract of $E$. bengalensis (Roxb.) Hook. $\mathrm{f}$. 
Table 1. Interaction of bioactive phytochemicals of $E$. bengalensis (Roxb.) Hook. f.with QS transcriptional regulatory protein, LasR of $P$. aeruginosa PAO1 expressed in terms of docking energy (kcal.mol), hydrogen bonds and hydrophobic residues

\begin{tabular}{|c|c|c|c|c|}
\hline & \multirow[t]{2}{*}{ Compounds/Ligands } & \multicolumn{3}{|c|}{ LasR } \\
\hline & & $\begin{array}{l}\text { Docking score } \\
\text { (kcal/mol) }\end{array}$ & $\begin{array}{l}\text { Hydrogen } \\
\text { bond }\end{array}$ & $\begin{array}{l}\text { Hydrophobic } \\
\text { residues }\end{array}$ \\
\hline 1. & $\begin{array}{c}\text { C12-HSL } \\
\text { (Natural ligand) }\end{array}$ & -7.293 & Arg 61, Thr 75 & $\begin{array}{l}\text { Leu } 36, \text { Tyr } 47, \text { Tyr } 56, \\
\text { Trp 60, Val 76, Trp } 88, \\
\text { Tyr 93, Thr } 115, \text { Ser } 129\end{array}$ \\
\hline 2. & Phytol & -6.905 & Leu 110 & $\begin{array}{l}\text { Leu } 36, \text { Tyr 47, Ala 50, } \\
\text { lle 52, Tyr 56, Tyr 64, } \\
\text { Ala 70, } \operatorname{Trp} 88, \text { Phe } 102\end{array}$ \\
\hline 3. & $\begin{array}{c}\text { Trimethyl[4-(1,1,3,3,- } \\
\text { tetramethylbutyl) } \\
\text { phenoxy] silane }\end{array}$ & -5.889 & No H-bond & $\begin{array}{c}\text { Leu 36, Tyr 47, lle 52, } \\
\text { Trp 60, Tyr 64, Ala 70, } \\
\text { Thr 75, Val 76, }\end{array}$ \\
\hline 4. & $\begin{array}{c}\text { 2-Hydroxyethyl- } \\
\text { hydrazine }\end{array}$ & -4.818 & $\begin{array}{l}\text { Tyr 56, Asp 73, } \\
\text { Tyr 93, Ser } 129\end{array}$ & $\begin{array}{l}\text { Leu } 36, \operatorname{Trp} 60, \text { Tyr } 64, \\
\text { Thr } 75, \operatorname{Trp} 88, \text { Leu } 110\end{array}$ \\
\hline
\end{tabular}

site residues (Arg-61, Thr-75) where autoinducer C12-homoserine lactone (C12-HSL) interacts with LasR protein ${ }^{19}$. The above prepared grid was used for docking. The ligand compounds were obtained from PubChem database and submitted for preparation in Ligprep module 2.5 in Schrodinger suite and the prepared protein and ligand were subjected for docking.

\section{Statistical Analysis}

All the experiments were performed in triplicates and the data was presented as mean \pm standard deviation (SD).

\section{RESULTS}

Determination of antioxidant activity DPPH free radical scavenging activity

E. bengalensis (Roxb.) Hook. f. extract exhibited significant DPPH radical scavenging in a concentration dependent manner. The plant extract showed a DPPH radical scavenging potential of $76.84 \pm 4.72 \%$ at a concentration of $500 \mu \mathrm{g} / \mathrm{ml}$ with an $\mathrm{IC}_{50}$ of $310.43 \mu \mathrm{g} / \mathrm{ml}$ (Fig. 1).

\section{Reducing power activity}

E. bengalensis (Roxb.) Hook. f. showed significant reducing power with concomitant increase in the concentration of plant extract. The increasing reducing power of plant extract was corresponded with the increase in optical density from 0.1377 at $100 \mu \mathrm{g} / \mathrm{ml}$ to 0.2115 At $500 \mu \mathrm{g} / \mathrm{ml}$ (Fig. 2).

\section{Hydroxyl radical scavenging activity}

A concentration dependent increase in hydroxyl radical scavenging was observed with concomitant increase in concentrations (100-500 $\mu \mathrm{g} / \mathrm{ml}$ ) of ethanolic leaf extract of $E$. bengalensis (Roxb.) Hook. f. The plant extract achieved a scavenging of $67.37 \pm 4.35 \%$ with an $I_{50}$ of 217.63 $\mu \mathrm{g} / \mathrm{ml}$ (Fig. 3).

Total antioxidant activity

The total antioxidant activity of $E$. bengalensis (Roxb.) Hook. f. significantly increased with an increase in concentration from 100 to 500 $\mu \mathrm{g} / \mathrm{ml}$. The ethanolic leaf extract of $E$. bengalensis (Roxb.) Hook. f. showed an ascorbic acid equivalent of $440.49 \mu \mathrm{g} / \mathrm{ml}$ at $500 \mu \mathrm{g} / \mathrm{ml}$ (Fig. 4).

Determination of anti QS and anti-biofilm activity Determination of MIC

The MIC of E. bengalensis (Roxb.) Hook. $\mathrm{f}$. extract against $P$. aeruginosa PAO1 was observed to be $1000 \mu \mathrm{g} / \mathrm{ml}$ and sub-MIC was fixed at 250 and $500 \mu \mathrm{g} / \mathrm{ml}$. All the anti QS and anti-biofilm activities were performed at sub-MIC level.

Violacein inhibition activity against $C$. violaceum

On treatment with sub-MICof $E$. bengalensis (Roxb.) Hook. f., violacein production in C. violaceum was significantly inhibited by 41.56 \pm 3.86 and $79.58 \pm 4.13 \%$ respectively (Fig. 5 ).

Pyocyanin inhibition activity against $P$. aeruginosa PAO1

A concentration dependent increase 


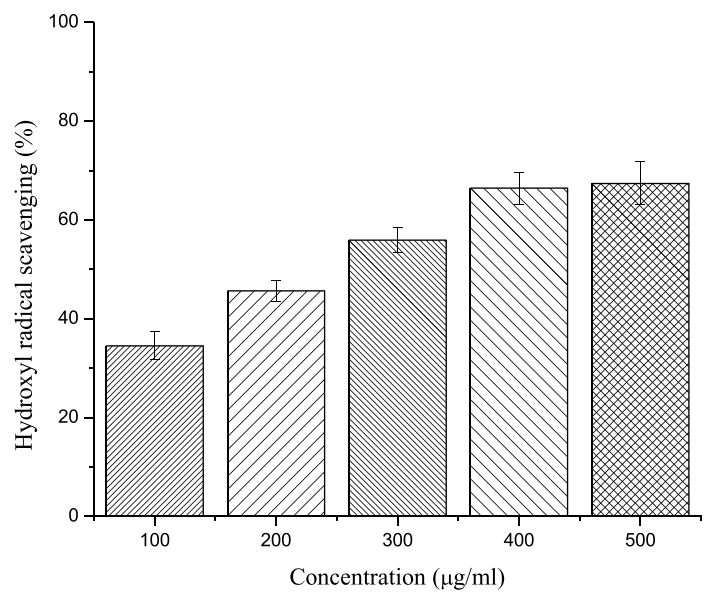

Fig. 3. Hydroxyl radical scavenging activity of different concentrations $(100-500 \mu \mathrm{g} / \mathrm{ml})$ of ethanolic leaf extract of E. bengalensis (Roxb.) Hook. f.

in the inhibition of Pyocyanin production was observed when P. aeruginosa PAO1 was treated with sub-MICof $E$. bengalensis (Roxb.) Hook. f. with an inhibition of $54.94 \pm 4.95$ and $76.31 \pm 4.03 \%$ respectively (Fig. 5).

\section{Inhibition of bacterial motility}

On treatment with sub-MIC $(500 \mu \mathrm{g} / \mathrm{ml})$ of $E$. bengalensis (Roxb.) Hook. f., a significant decrease in swimming and swarming motility was observed as compared to untreated control (Fig. 6).

\section{Anti-biofilm activity using CLSM analysis}

E. bengalensis (Roxb.) Hook. f. exhibited a significant anti-biofilm activity against the $24 \mathrm{~h}$ biofilms of $P$. aeruginosa PAO1 as observed from CLSM analysis as compared to untreated control with comparatively thicker and highly compact biofilm architecture (Fig. 7).

\section{GC-MS analysis}

From the GC-MS analysis and NIST library search, 2-hydroxy propoanamide and phytol were identified with relatively higher peak area (\%) of 30.853 and $17.354 \%$ respectively. The GC-MS spectrum and the identified compounds were presented in Fig. 8.

Molecular Docking studies

Molecular docking studies of $E$. bengalensis (Roxb.) Hook. f. revealed that, phytol exhibited a docking score of $-6.905 \mathrm{kcal} / \mathrm{mol}$ for LasR which was relatively close to the binding energy of the interaction of LasR with its natural

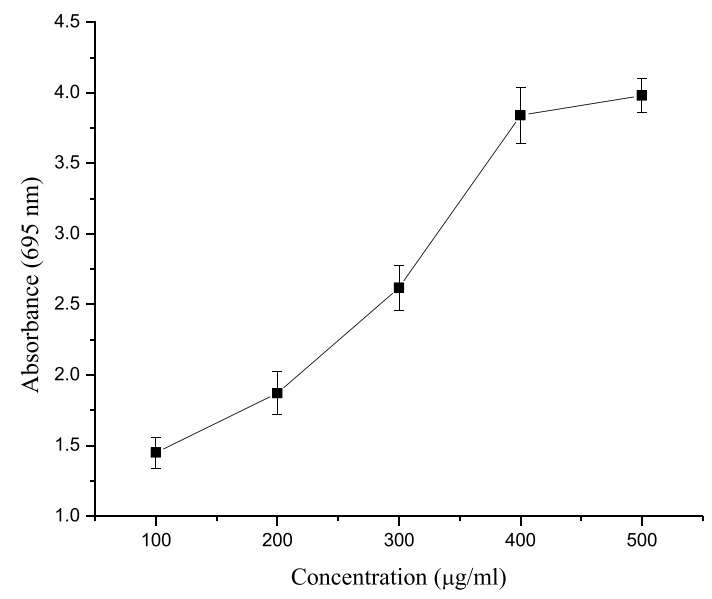

Fig. 4. Total antioxidant activity of different concentrations $(100-500 \mu \mathrm{g} / \mathrm{ml})$ of ethanolic leaf extract of E. bengalensis (Roxb.) Hook. f.

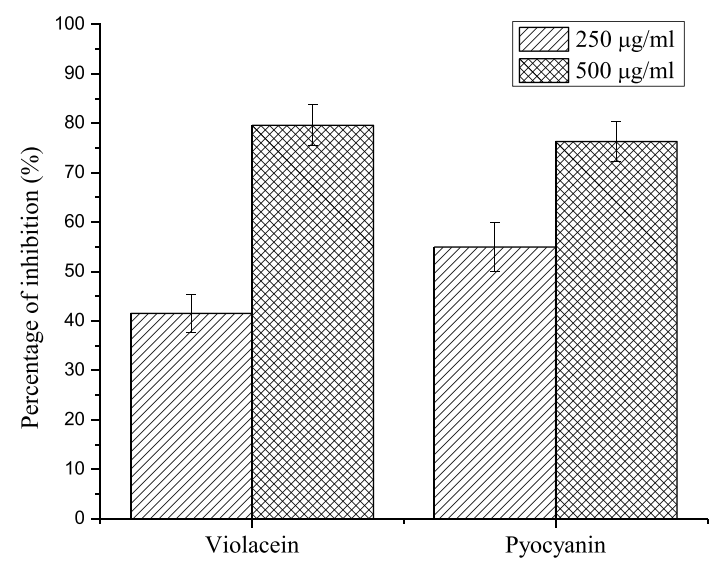

Fig. 5. Effect of sub-MIC concentrations of $E$. bengalensis (Roxb.) Hook. f. $(250,500 \mu \mathrm{g} / \mathrm{ml})$ on production of violacein in biomarker strain, $C$. violaceum and pyocyanin in test bacteria, $P$. aeruginosa PAO1

ligand (-7.293 kcal/mol). Besides, 2-hydroxyethyl hydrazine showed a docking score of -4.818 with four $\mathrm{H}$-bonding between with the transcriptional regulatory protein, LasR (Table 1, Fig. 9).

\section{DISCUSSION}

The ethnomedicinal values of medicinal plants as folkloric medicines for the treatment of diseases and microbial infections have been used since human civilization. In the present study, the ethanolic leaf extract of $E$. bengalensis (Roxb.) Hook. f. was evaluated for its antioxidant potential and ability to down regulate the production of QS 


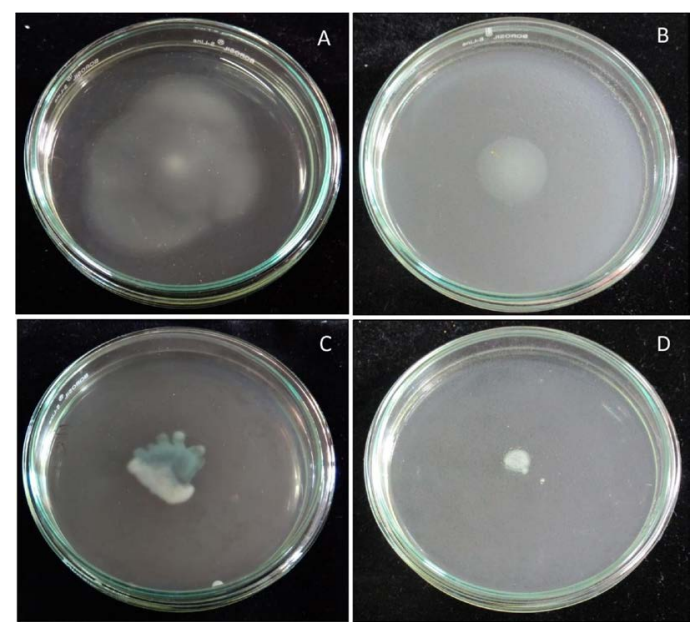

Fig. 6. Anti-swimming and anti-swarming activity of ethanolic leaf extract of $E$. bengalensis (Roxb.) Hook. f. (A) Swimming motility of $P$. aeruginosa PAO1 (untreated control), (B) Swimming motility of E. bengalensis (Roxb.) Hook. f. treated P. aeruginosa PAO1, (C) Swarming motility of $P$. aeruginosa PAO1 (untreated control), (D) Swarming motility of E. bengalensis (Roxb.) Hook. $f$. treated $P$. aeruginosa PAO1.

controlled virulence factors and biofilm dynamics. DPPH free radical assay is a standard method to evaluate the radical scavenging potential of natural plant products. In the present study, $E$. bengalensis (Roxb.) Hook. f. significantly scavenged the DPPH free radicals with an $\mathrm{IC}_{50}$ of $310.43 \mu \mathrm{g} /$ $\mathrm{ml}$ which was comparatively equivalent to the antioxidant potential of Croton caudatus which showed an $\mathrm{IC}_{50}$ of $305.39 \mu \mathrm{g} / \mathrm{ml}^{20}$. The ability to
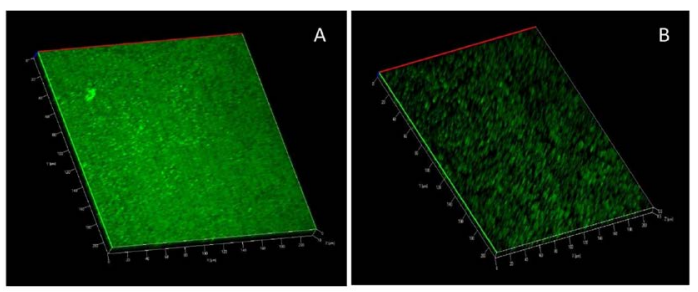

Fig. 7. Anti-biofilm activity of ethanolic leaf extract of $E$. bengalensis (Roxb.) Hook. f. against $P$. aeruginosa PAO1 biofilm (A) Biofilm formation in P. aeruginosa PAO1 (untreated control), (B) Inhibition of biofilm formation in $P$. aeruginosa $\mathrm{PAO} 1$ on treatment with $E$. bengalensis (Roxb.) Hook. f.

reduce $\mathrm{Fe}^{3+}$ to $\mathrm{Fe}^{2+}$ by forming the Prussian blue complex is determined by reducing power assay. The increasing reducing power of any natural plant products is generally correspond with the increase in the optical density. In the present study, with the increase in concentration from 100-500 $\mathrm{gg} /$ $\mathrm{ml}$, a concomitant increase in the optical density of the reaction mixture treated with plant extract was observed which was in accordance to earlier report ${ }^{21}$. Hydroxyl radicals are one of the highly reactive free radicals causing severe oxidative stress in the biological macromolecules. $E$. bengalensis (Roxb.) Hook. f. exhibited an increase in the hydroxyl radical scavenging with subsequent increase in concentration from $100-500 \mu \mathrm{g} / \mathrm{ml}$ with an IC ${ }_{50}$ of $256.97 \mu \mathrm{g} / \mathrm{ml}$ which was relatively higher as compared to earlier report ${ }^{9}$. The ability of $E$. bengalensis (Roxb.) Hook. $f$. in forming the phosphomolybdate complex was determined and expressed in terms of AAE. E. bengalensis (Roxb.)

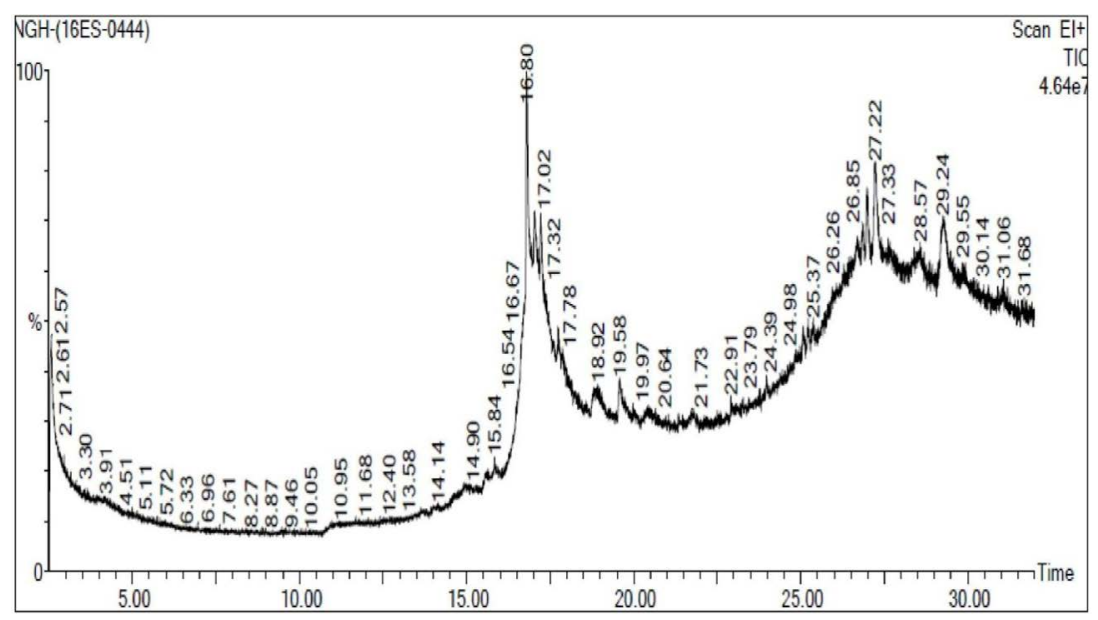

Fig. 8. GC-MS spectrum of E. bengalensis (Roxb.) Hook. f. extract. 


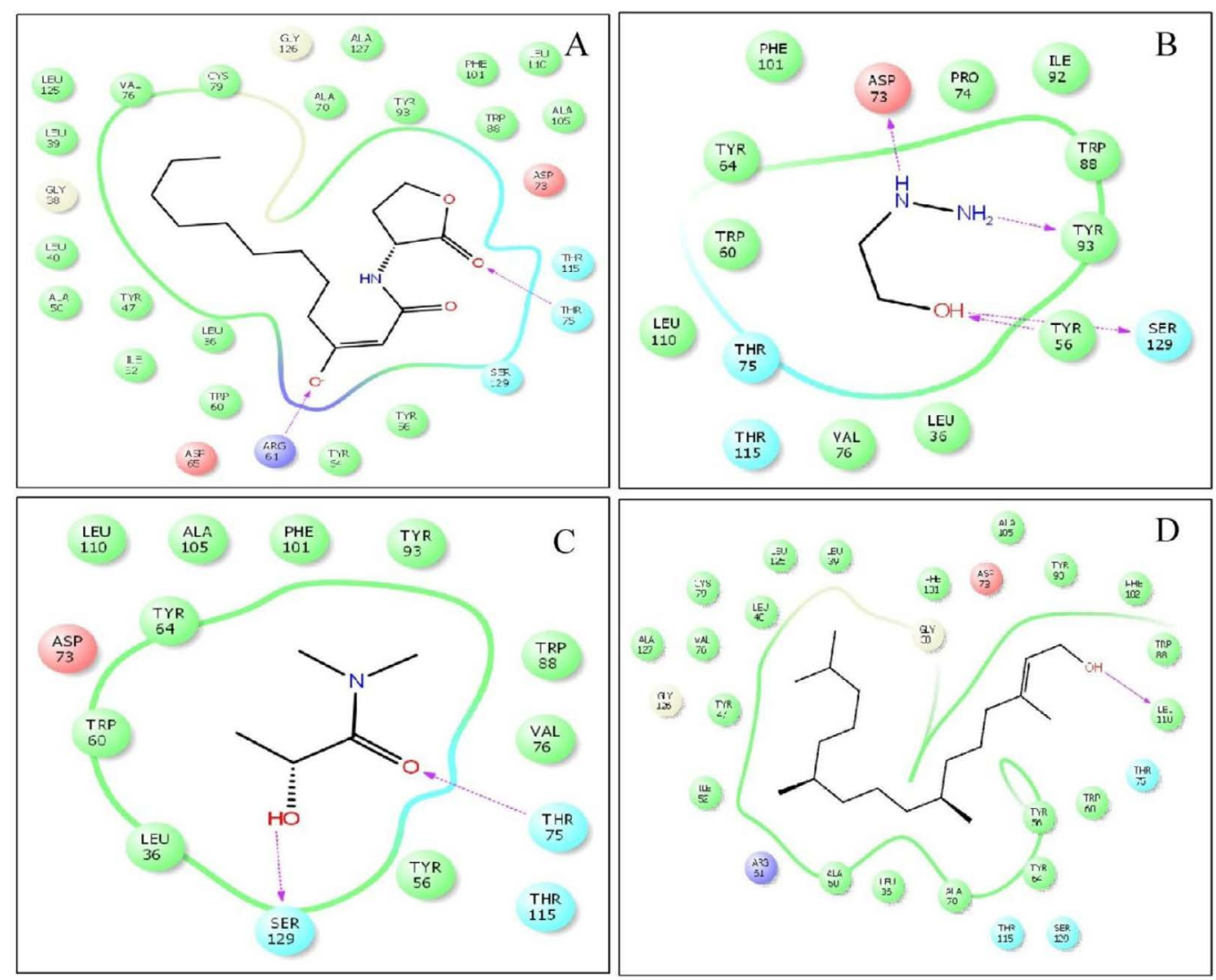

Fig. 9. Molecular docking studies of the phytochemicals identified from the ethanolic leaf extract of $E$. bengalensis (Roxb.) Hook. f.and their interactions with the QS transcriptional regulator protein, LasR as compared to the interaction of natural ligand (C12-HSL). (A). 2D docked conformation of C12-HSL into the active pocket of LasR, (B) 2D docked conformation of 2-Hydroxyethylhydrazine into the active site of LasR, (C) 2D docked conformation of Propanamide, 2-hydroxy into the active site of LasR, (D) 2D docked conformation of phytol into the active site of LasR.

Hook. f. showed an ascorbic acid equivalent of $440.49 \mu \mathrm{g} / \mathrm{ml}$.

In recent times, the QS network in microorganisms also play crucial role in inducing oxidative stress in the living organisms by regulating the production of an array of virulence factors and hence served as an important drug target. In this context, the present study aims to evaluate the QS inhibitory potential of $E$. bengalensis (Roxb.) Hook. f. against the nosocomial pathogen, $P$. aeruginosa PAO1. At sub-MIC level, the ethanolic extract of $E$. bengalensis (Roxb.) Hook. f. significantly inhibited the production of violacein pigment in the biomarker strain, $C$. violaceum suggesting the efficacy of using E. bengalensis (Roxb.) Hook. f. as potent QS inhibitor in our test pathogen, $P$. aeruginosa
PAO1. P. aeruginosa PAO1 constitutes a highly complex QS network for the production of several cytotoxic phenazine compounds, particularly the pyocyanin pigment. Pyocyanin plays a substantial role during host infection process by inducing oxidative stress ${ }^{22}$. E. bengalensis (Roxb.) Hook. f. significantly attenuated the production of Pyocyanin by $76.31 \pm 4.03 \%$ which was significantly higher than the earlier report at $500 \mu \mathrm{g} / \mathrm{ml}^{23}$. The swarming motility in $P$. aeruginosa regulates the formation and development of biofilm ${ }^{24}$. $E$. bengalensis (Roxb.) Hook. f. altered the swarming motility of $P$. aeruginosa PAO1 as compared to untreated control suggesting its ability to regulate the flagellar-driven biofilm formation. The CLSM analysis further confirmed the biofilm inhibitory potential of $E$. bengalensis (Roxb.) Hook. f. as 
evident from comparatively thinner biofilm architecture as compared to highly compact and thicker biofilm architecture in untreated control ${ }^{16}$. The presence of phytol in the crude extract of E. bengalensis (Roxb.) Hook. f. suggested the efficacy of plant extract in scavenging free radicals and also combating QS regulated virulence and biofilm formation in $P$. aeruginosa PAO1 $1^{25,26}$. From the molecular docking, it was observed that phytol exhibited promising docking affinity with LasR which is relatively close to that of natural ligand suggesting the efficacy of phytol in competitive binding with LasR and altering the LasR mediated bacterial virulence. In addition, 2-Hydroxyethylhydrazine showed a strong binding affinity with LasR by forming four $\mathrm{H}$-bonds which was comparatively higher than the natural ligand itself.

\section{CONCLUSION}

The present study furnished the antioxidant and anti-infective potential of $E$. bengalensis (Roxb.) Hook. f. extract. The ability of E. bengalensis (Roxb.) Hook. f. in down regulation of QS associated behaviours of $P$. aeruginosa PAO1 further confirmed the use of natural plant materials as a safe and alternative strategy to combat microbial infection. The presence of phytol in the ethanolic extract could be responsible for the attenuation of QS regulated pyocyanin production and biofilm formation. The molecular docking studies provided an insight into the mechanism of QS inhibition by targeting the transcriptional regulator, LasR of the QS network. The promising anti QS and anti-biofilm activity of $E$. bengalensis (Roxb.) Hook. f. in the present study have provided new and alternative avenues to exploit the plant extract in controlling microbial infections caused by other pathogenic bacteria. The present study will thus provide a support system to current drug discovery programmes in the development of novel anti-infectives.

\section{ACKNOWLEDGEMENTS}

The authors are thankful to Bharathidasan University, Tiruchirapalli, Tamilnadu, India for providing the CLSM facility. The authors would also like to thank Sophisticated Instrumentation Facility (SIF), VIT University, Vellore, Tamilnadu,
India for GC-MS analysis. The authors hereby also acknowledge the Centre for Bioinformatics, Pondicherry University for providing facility for molecular docking.

\section{CONFLICT OF INTEREST}

conflict of interest.

The author declares that there are no

\section{REFERENCES}

1. Elochukwu C Generation and reaction of free radicals in the human body: a major cause of aging and chronic degenerative diseases. E. C. Nutrition, 2015; 1(3): 132136.

2. Lobo V, Patil A, Phatak A, Chandra N. Free radicals, antioxidants and functional foods: Impact on human health. Pharmacognosy Review, 2010; 4(8): 118-126.

3. Xu D P, Li Y, Meng X, Zhou T, Zhou Y, Zheng J, Zhang JJ, Li $H B$. Natural antioxidants in foods and medicinal plants: Extraction, assessment and resources. International Journal of Molecular Sciences, 2017; 18(1): 96.

4. Kasote D M, Katyare SS, Hegde MV, Bae H). Significance of antioxidant potential of plants and its relevance to therapeutic applications. International Journal of Biological Sciences, 2015; 11(8): 982-991.

5. Ivanov A V, Bartosch B, Isaguliants M G. Oxidative stress in infection and consequent disease. Oxidative Medicine and Cellular Longevity, 2017; 2017:3496043.

6. Bhargava N, Sharma P, Capalash N. Pyocyanin stimulates quorum sensing-mediated tolerance to oxidative stress and increases persister cell populations in Acinetobacter baumannii. Infection and Immunity, 2014; 82(8): 3417-3425.

7. Datta S, Jana D, Maity T R, Samanta A, Banerjee R. Piper betle leaf extract affects the quorum sensing and hence virulence of Pseudomonas aeruginosa PAO1. 3 Biotech., 2016; 6: 18.

8. Hong $\mathrm{Y}$, Lin $\mathrm{S}$, Jiang $\mathrm{Y}$, Ashraf $\mathrm{M}$. ariation in contents of total phenolics and flavonoids and antioxidant activities in the leaves of 11 Eriobotrya species. Plant foods for Human Nutrition, 2008; 63: 200.

9. Pavithra K, Vadivukkarasi S. Evaluation of free radical scavenging activity of various extracts of leaves from Kedrostis foetidissima (Jacq.) Cogn. Food Science and Human Wellness, 2015; 4(1): 42-46.

10. Singh R, Shushni MAM, Belkheir A. Antibacterial and antioxidant activities of Mentha piperita L. Arabian Journal of Chemistry, 2015; 8(3): 322-328.

11. Tounkara F, Bashari M, Le G W, Shi Y H. Antioxidant activities of roselle (Hibiscus sabdariffa L.) seed protein hydrolysate and its derived peptide fractions. International Journal of Food Properties, 2014; 17(9): 1998-2011.

12. Do Q D, Angkawijaya A E, Tran-Nguyen P L, Huynh L H, Soetaredjo F E, Ismadji S, Ju Y H. Effect of extraction solvent on total phenol content, total flavonoid content, and antioxidant activity of Limnophila aromatica. Journal of Food and Drug Analysis, 2014; 22(3): 296-302. 
13. El-Shaer S, Shaaban M, Barwa R, Hassan R. Control of quorum sensing and virulence factors of Pseudomonas aeruginosa using phenylalanine arginyl b-napthylamide. Journal of Medical Microbiology, 2016; 65: 1194-1204.

14. Choo J H, Rukayadi Y, Hwang J K. Inhibition of bacterial quorum sensing by vanilla extract. Letters in Applied Microbiology, 2006; 42: 637-641.

15. Kordbacheh $\mathrm{H}$, Eftekhar F, Ebrahimi SN. Antiquorum sensing activity of Pistacia atlantica against Pseudomonas aeruginosa PAO1 and identification of its bioactive compounds. Microbial Pathogenesis, 2017; 110: 390-398.

16. Packiavathy I A, Priya S, Pandian SK, Ravi A V. Inhibition of biofilm development of uropathogens by curcumin - an anti-quorum sensing agent from Curcuma longa. Food Chemistry, 2014; 148: 453-460.

17. Zhou J W, Luo $H$ Z, Jiang $H$, Jian $T$ K, Chen Z Q, Jia A Q. Hordenine: A novel quorum sensing inhibitor and antibiofillm agent against Pseudomonas aeruginosa. Journal of Agricultural and Food Chemistry, 2018; 66: 1620-1628.

18. Gomathi D, Kalaiselvi M, Ravikumar G, Devaki K, Uma C. GC-MS analysis of bioactive compounds from the whole plant ethanolic extract of Evolvulus alsinoides (L.) L. Journal of Food Science and Technology, 2015; 52(2): 1212-1217.

19. Bottomley M J, Muraglia F, Bazzo R, Carfi A. Molecular insights into quorum sensing in the human pathogen Pseudomonas aeruginosa from the structure of the virulence regulator LasR bound to its autoinducer. Journal of Biological Chemistry, 2007; 282: 1359213600.

20. Subhaswaraj P, Sowmya M, Bhavana V, Dyavaiah
M, Siddhardha B. Determination of antioxidant activity of Hibiscus sabdariffa and Croton caudatus in Saccharomyces cerevisiae model system. Journal of Food Science and Technology, 2017; 54(9): 2728-2736.

21. Baba S A, Malik A H, Wani Z A, Mohiuddin T, Shah Z, Abbas N, Ashraf N. Phytochemical analysis and antioxidant activity of different tissue types of Crocus sativus and oxidative stress alleviating potential of saffron extract in plants, bacteria, and yeast. South African J Bot, 2015; 99: 80-87.

22. Chong $Y M$, Yin W F, Ho C Y, Mustafa M R, Hadi H A, Awang K, Narrima P, Koh C L, Appleton DR, Chan K G. Malabaricone $C$ from Myristica cinnamomea exhibits anti-quorum sensing activity. Journal of Natural Product, 2011; 74(10): 2261-2264.

23. Ganesh P S, Rai V R. Attenuation of quorum sensing dependent virulence factors and biofilm formation by medicinal plants against antibiotic resistant Pseudomonas aeruginosa. Journal of Traditional and Complementary Medicine, 2018; 8(1): 170-177.

24. Husain F M, Ahmad I, Al-thubiani A S, Abulreesh $\mathrm{HH}$, AlHazza I M, Aqil F. Leaf extracts of Mangifera indica L. inhibit quorum sensing regulated production of virulence factors and biofilm in test bacteria. Frontiers in Microbiology, 2017; 8: 727.

25. Santos CCMP, Salvadori M S, Mota V G, Costa L M, de Almeida AAC, de Oliveira GAL, Costa J P, de Sousa D P, de Frietas R M, de Almeida R N. Antinociceptive and antioxidant activities of phytol in vivo and in vitro models. Neuroscience Journal, 2013; 2013: Aricle ID 949452

26. Pejin B, Ciric A, Glamoclija J, Nikolic M, Sokovic M. In vitro anti-quorum sensing activity of phytol. Natural Product Research, 2015; 29(4): 374-377. 